\title{
OUTWARD FOREIGN DIRECT INVESTMENT AND ECONOMIC GROWTH IN CHINA: EVIDENCE FROM ASYMMETRIC ARDL APPROACH
}

\author{
Usman ALI ${ }^{1}$, Wei SHAN ${ }^{*}$, Jian-Jun $\mathrm{WANG}^{3 * *}$, Azka AMIN ${ }^{4}$ \\ ${ }^{1,3}$ Faculty of Management and Economics, Dalian University of Technology, Dalian, China \\ ${ }^{2}$ Department of Ophthalmology, the Second Hospital of Dalian Medical University, \\ Dalian, China \\ ${ }^{4}$ The Centre for Economic Research, Shandong University, Jinan, China
}

Received 29 December 2017; accepted 19 September 2018

\begin{abstract}
The current study explored the dynamics between economic growth and overseas investment, using time series annual data from China. For empirical analysis, we utilized asymmetric ARDL technique, which documents the potential asymmetric effects of outward foreign direct investment on economic growth in both the long run and short run. The empirical results suggest that ignoring the intrinsic asymmetries may conceal the true information about the equilibrium relationship among the variables and thus lead to misleading results. Particularly, the findings revealed that economic growth in China responds positively but differently to an increase and decrease in its overseas investment. The empirical evidence obtained through asymmetric model seemed to be superior to that of symmetric model and thus leads to more efficient policymaking to achieve sustainable economic development. Our study contributes to the existing literature by providing new insights on the outward foreign direct investment-led growth hypothesis. The findings suggest that firms investing abroad can bring source country benefits by securing access to key input factors and accessing advanced foreign technology.
\end{abstract}

Keywords: outward FDI, economic growth, time series, asymmetric ARDL, dynamic multiplier, China.

JEL Classification: F23, O10.

\section{Introduction}

China's rapid integration into the global economy is the most profound business phenomenon that is occurring through different channels. Particularly, its linkages to other countries through overseas investment has accelerated exponentially to the level where China is now one of the largest source of FDI in the world. In 1999, Chinese Government adopted "go global" strategy to encourage and support domestic firms to enhance their businesses in

\footnotetext{
${ }^{\star}$ Joint first author

${ }^{*}$ Corresponding author. E-mail: drwangjj@dlut.edu.cn

Copyright () 2018 The Author(s). Published by VGTU Press
}

This is an Open Access article distributed under the terms of the Creative Commons Attribution License (http://creativecommons. org/licenses/by/4.0/), which permits unrestricted use, distribution, and reproduction in any medium, provided the original author and source are credited. 
foreign markets (You \& Solomon, 2015). As a result, outward FDI from the country grew rapidly, making China the second largest overseas investor ${ }^{1}$ in the world right after the United States. In 2016, the cumulative stock of China's outward foreign direct investment (ODI) has reached over $\$ 180$ billion from $\$ 128$ billion in 2015, a rise of about $44 \%$ over a year (UNCTAD, 2017). This exponential rise in ODI from China caused a remarkable shift in the country's position from previously being the net recipient to the net source of FDI (UNCTAD, 2017). Such a dramatic rise in the country's ODI is mainly motivated by the advance technology and other strategic assets seeking such as brand names and natural resources seeking (Cai, 1999; Li, Strange, Ning, \& Sutherland, 2016).

The emergence of China as a leading source of ODI concerns the economy because it has important development implications, and requires paying greater attention to the role ODI plays in further advancing the economic development of the country. Our study seeks to inquire whether China's increasing ODI has stimulated economic growth in the country. Despite its relevance and importance for China, very little attention is paid to the contribution which ODI makes to the overall economic growth in the country on an aggregate level. Our study fills this gap by using aggregate level data of ODI and economic growth, and thus provides significance policy implications at macroeconomic level.

Theoretically, ODI stimulates economic growth in the source country in two ways. Firstly, ODI generates technological diffusion from the developed world to the home country which in turn enhances the efficiency of domestic investment ( $\mathrm{Li}$ et al., 2016). Secondly, firms investing abroad secure access to cheaper raw materials, to produce final goods at lower production costs and in greater volume, and thus increase their competitiveness in both domestic and foreign markets (e.g., Desai, Foley, \& Hines, 2005; Herzer, 2008). As a result, the whole domestic economy gets benefit through backward and forward production linkages with multinational enterprises (MNEs). Unfortunately, the empirical evidences on the home country's economic growth effects of ODI are more contentious in empirical studies than in theoretical studies. Some studies reported positive impact of ODI on economic growth (Knoerich, 2017; Lee, 2010), others postulated a negative relationship between these two variables (Stevens \& Lipsey, 1992; Goh \& Wong, 2014). For example, Hsu, Wang and Clegg (2015) argued that Chinese MNEs have positive impact on its exports and domestic investment through increasing demands for imports from the host country. Against this, Al-Sadiq (2013) and Goh and Wong (2014) argued that ODI involves relocation of scarce financial funds from domestic to overseas investment and thus entails substitution between domestic investment and ODI, which ultimately reduces domestic output. The controversy has mainly arisen due to the notion that if ODI substitutes domestic investment, it will also decelerate economic growth in the source country (Ali \& Wang, 2018). However, a more recent review study by Knoerich (2017) has tried to eliminate the controversy by arguing that returns from ODI promote economic growth if they help mitigate certain developmental problems of source country, such as technology constraint or resources shortages. But the empirical evidences on the home country's economic growth effects of ODI has been lacking for developing countries.

\footnotetext{
${ }^{1}$ Throughout the paper, we use the terms 'overseas investment', 'outbound investment' and outward investment interchangeably.
} 
Another problem with assessing the true effects of ODI on economic growth is the use of alternative econometric techniques, which assume that the adjustment between overseas investment and economic growth is symmetric i.e. a rise is ODI stimulates economic growth and vice versa. In fact, the substitution between ODI and domestic investment implies that both an increase and decrease in ODI may increase economic growth in the source country, indicating the potential asymmetric effects of ODI. For example, a decrease in overseas investment makes funds available for domestic investment which in turn stimulates economic growth. Given the possible asymmetries in the relationship between ODI and economic growth, there is a need for a proper asymmetric test. Unfortunately, all the existing studies have neglected this necessity.

In Chinese perspective, the mechanism through which ODI effects domestic economy is not so straightforward. You and Solomon (2015) argue that the substitution between ODI and domestic investment does not hold true in case of China because of two reasons. Firstly, the saving ratio of China is the highest of all the major economies of the world that helped China to accelerate domestic and overseas investment. Secondly, a part of Chinese overseas investment is also financed through sources other than internal financial market, implying that ODI from the country is not discouraging domestic enterprises. On the other hand, the studies have shown that ODI has positive impact on economic growth in China through generating technology diffusion (Li et al., 2016) and securing access to relatively larger foreign markets and cheaper input factors (You \& Solomon, 2015). The major shortcoming of these studies, however, is that they provide only limited inference from a macroeconomic perspective because all these studies mainly focus on domestic investment effects of ODI using firm- and industry-level microeconomic data, but the studies focusing on the economic growth effects of ODI, especially at macroeconomic level, are scarce. Our study fills this gap by analysing the impact of ODI on economic growth at an aggregate level. Moreover, unlike previous studies that implicitly assume linear effects of ODI on economic growth, we develop a non-linear model to capture the possible asymmetric effects of ODI on economic growth. For empirical estimation, our study utilizes asymmetric or nonlinear autoregressive distributive lag (NARDL) model recently developed by Shin, Yu, and Greenwood-Nimmo (2014). The main advantage of NARDL is that it captures both the long run and short run asymmetries unlike standard ARDL and other existing time series econometric techniques that simply presume linear or symmetric effects of the movements of a regressor on a regressand.

This paper is organized as follows. The next section provides some insights from theoretical and empirical literature. Section 2 describes model and estimation methodology intend for this study. Empirical results and discussion of the findings are given in section 3 followed by the conclusions in final section.

\section{A review of theoretical and empirical literature}

The traditional theories on the emergence of multinational enterprises are based on the views that firm-specific and oligopolistic advantages already possessed by the MNEs are the essential prerequisite for the happening of FDI (Dunning, 2001). The most common traditional theories regard FDI as an activity to exploit competitive assets (Dunning, 2001; Knoerich, 
2017), underscoring the idea that MNEs are economically strong and dominant when conducting investment in the host country. But the recent emergence of MNEs from developing countries have exposed the flaws in traditional theories to fully explain the occurrence of cross border investment. These recent advancement in FDI theory posits that, in addition to asset exploitation, firms also conduct overseas investment in order to seek or enhance existence assets (UNCTAD, 2006; Wesson, 1999). Case studies examining the emergence of MNEs from less advanced countries, such as China and Indonesia, suggest that firms from emerging economies are motivated mainly by the natural resources, foreign markets and technology seeking while making cross border investment decisions (Lecraw, 1993; Child \& Rodrigues, 2005; Knoerich, 2017). The assets seeking views seem more suitable because it helps foster the development of the home country through direct transfer and utilization of assets in the source country or through indirect linkages of MNEs with parent country.

Empirically, an extensive body of literature has been devoted to investigate the linkages between inward FDI and economic growth in the host countries (see, e.g., Lai, Peng, \& Bao, 2006; Fu, 2008; Li et al., 2016). But the research on the relationship between outward FDI and economic growth is relatively scarce and focused mainly on industrial countries such as United States, Japan and EU countries (Hsu et al., 2015). These studies suggest that the impact of ODI is small but positive for the source country (Herzer, 2008; Knoerich, 2017). For instance, using cross country and time series data for United States, Herzer $(2008,2010)$ provides empirical evidence to show that ODI stimulates economic growth and output in the home economies. For 12 EU countries, Sunesen, Jespersen, and Telle (2010) conclude that ODI improves competitiveness and productivity of domestic firms. Moreover, Hijzen, Jean, and Mayer (2011) also report positive effects of ODI on employment and export growth in France. Tan, Goh, and Wong (2016) utilized panel data of 8 ASEAN countries and reported complementary effects of both the inward and outward FDI on domestic investment.

In particular case of China, very limited research is devoted to examine the effects of ODI on domestic economy. These studies mainly focused on domestic investment (Zhang, Chen, \& Yang, 2011; You \& Solomon, 2015) or technology transfer effects of ODI (Li et al., 2016), while the economic growth implications of ODI are not examined so far for China. For instance, Zhang et al. (2011) study uses time series data in a VAR setting and concludes that ODI has positive impact on domestic capital formation and plays an important role in the upgradation of industrial structure in the country. By using industrial level data, You and Solomon (2015) extend this idea to show that ODI stimulates domestic investment in China. Meanwhile, Li et al. (2016) use provincial level data of China and show that ODI has significant and positive effect on domestic innovation and technology development. Nonetheless, all these studies have examined the firm level and industry level effects of ODI on domestic investment and technology development, and provide little or no inference for overall economic growth at macroeconomic level for China.

There are also some studies which show that ODI has negative impact on the source country's economic activities through decreasing domestic investment (see, e.g., Stevens \& Lipsey, 1992; Desai et al., 2005; Al-Sadiq, 2013; Goh \& Wong, 2014; Ali \& Wang, 2018). For instance, Al-Sadiq (2013) and Goh and Wong (2014) noted that ODI involves reallocation of funds from domestic to overseas investment and thus entails substitution between domestic 
investment and ODI. Nonetheless, it is not necessary that a substitution between ODI and domestic investment also decelerates economic growth, rather ODI can stimulate economic growth through improving total factor productivity (TFP) and reducing cost of production by combining production with foreign affiliates (Desai et al., 2005; Herzer, 2008; Weng Yang, \& Tu, 2010; Hsu et al., 2015). As pointed out by Eregha (2012), the positive economic growth effects of FDI might be due to a rise in TFP rather than the expansion in domestic capital stock.

A common feature of all the earlier studies is that they implicitly assumed symmetric relationship between ODI and economic growth in the source country. In reality, the effect of overseas investment on economic growth might not be symmetric i.e. it is not necessary that if an increase in ODI raises economic growth, a decrease in ODI will also decrease economic growth. In fact, the substitution between domestic and overseas investment implies that a decline in ODI makes funds available for domestic investment, implying greater economic activities in the home country. In other words, a decline in ODI might also accelerate economic growth in the source country indirectly through increasing domestic investment. However, the relative importance of domestic and overseas investment for the economic growth may differ. These considerations highlight the possible asymmetrical effects of ODI on economic growth, negating the common assumption of all the above mentioned studies that ODI has symmetric effects on economic growth. These intuitions require to pay greater attention to the asymmetric effects of ODI on economic growth which were neglected by the earlier studies. Our study fills this gap by using an asymmetric framework in case of China.

\section{Model specification and estimation method}

\subsection{Model specification}

The limits of neoclassical growth models to explain the sources of long-term economic growth led to a dissatisfaction with traditional theories which generally assume diminishing returns to capital by overlooking the role of technology change in the production function. Though Solow growth model introduces technology progress as a determinant of economic growth, however, the model considers it as an exogenous factor which is determined outside the production function. On the other hand, the models based on endogenous or new growth theories evade diminishing returns to capital by introducing technology change and human capital in the production process. The assumption of constant marginal product of capital, which is the most important theoretical difference between traditional and new growth theories, implies that investment in human capital and R\&D sector generates external economies and improves factor productivity which ultimately yield long-term economic growth. In addition, as argued by Todaro and Smith (2006), perhaps the most interesting contribution of endogenous growth model lies in explaining the role of FDI or international capital flows between developed and developing countries. According to this conception, FDI facilitates technology spillovers in the developing countries which in turn improves factor productivity and ensures long-run economic growth. This also seems relevant with the subject matter of this study. As we discussed in the literature review section, ODI fosters the development of 
home country through various channels of spillovers as well as backward linkage of MNEs with parent companies. These insights lead to an empirical framework that relates economic growth to FDI and other core variables as follow ${ }^{2}$ :

$$
y_{t}=\beta_{1} d_{t}+\beta_{2} c s_{t}+\beta_{3 t} l e_{t}+\beta_{4} i f_{t}+\beta_{5} o f_{t}+\varepsilon_{t},
$$

where $y_{t}$ is economic growth proxied by Real GDP per capita, $c s_{t}$ is capital stock measured as the ratio of gross fixed capital formation (or gross domestic investment) to GDP, $l e_{t}$ is life expectancy used to measure human capital ${ }^{3}$, if $f_{t}$ and $\mathrm{if}_{\mathrm{t}}$ stand for inward and outward FDI to GDP ratio, $d_{t}$ is a vector of deterministic terms such as constant and time trend, and $\varepsilon_{t}$ is the usual error term. Real GDP per capita and life expectancy are measured in logarithms, while $c f_{t}, o f_{t}$ and $\mathrm{if}_{\mathrm{t}}$ are given as GDP ratios.

The inclusion of all these variables is based on previous literature on FDI-growth nexus (Li \& Liu, 2005; Kotrajaras, 2010; Lee, 2010). Domestic investment is a conventional input factor and is expected to increase output growth in both traditional and new growth theories. It is also very much relevant in case of China because her growth model relies heavily on the accumulation of domestic investment (You \& Solomon, 2015). Human capital is meant to capture the effect of quality labour force on absorptive capacity necessary to gain from the flow of knowledge spillovers through FDI. Zhang (2006) noted that the positive effect of FDI on economic growth is conditional on the level of human capital in the host country. The sign of the coefficient of IDI $\left(\beta_{4}\right)$ is expected to be positive, ceteris paribus, a rise in IDI contributes to economic growth by raising domestic capital formation and generating technology diffusion (Goh \& Wong, 2014). Similarly, the coefficient of ODI $\left(\beta_{2}\right)$ is expected to be positive irrespective of its domestic investment effects. As we discussed in previous sections, the firms investing abroad can foster economic growth of the home country through direct transfer of the assets back in the parent country or indirectly through improving their competitiveness by accessing advanced technology, and yielding positive spillovers effects to the local firms in their parent country. Annual data for all these variables during 1982-2015 is obtained from World Bank databank (2017). The starting year of this dataset is determined by the availability date of data.

\subsection{Empirical methodology}

For empirical estimation, our study utilizes asymmetric or nonlinear autoregressive distributive lag (NARDL) ${ }^{4}$ model recently developed by Shin et al. (2014). This approach has some

\footnotetext{
2 This model is similar to the production function utilized by Zhang (2006) and Kotrajaras (2010) i.e, Y = F (A, K, $\mathrm{H}$ ), where A (technology) is endogenized as a function of FDI.

${ }^{3}$ Education is a commonly used proxy of human capital. Due to data unavailability on the commonly used indicators of education during the period of this study, we use life expectancy following Azman-Saini, Baharumshah, and Law (2010). It is also consistent with Barro and Sala-i-Martin (2004) who argue that economic growth responds positively to the level of human capital in form of health and education.

${ }^{4}$ Note that the asymmetry or nonlinearity is not in the sense that our parameters are quadratic or log-linear as defined usually. Actually it is a decomposed linear relationship of the effects of independent variable on dependent variable in ARDL to test if positive changes and negative changes in independent variable have different relationship (Shin et al., 2014).
} 
certain advantages over the existing estimation techniques (e.g., Error Correction Model (ECM), the Markov-switching ECM, the threshold ECM and the Smooth transition ECM) to jointly model the cointegration dynamics and asymmetries in the underlying variable. Besides it simplicity of estimation, it also provides a flexible framework by relaxing the assumption that the regressors should be integrated of the same order, which is in contrast to the ECM that requires this assumption hold true (Katrakilidis \& Trachanas, 2012). This technique is also relevant in present scenario as it allows to distinguish between linear and nonlinear cointegration, unlike the standard ARDL and other existing techniques that simply presume linear or symmetric effects of the movement of a regressor on a regressand (Fousekis, Katrakilidis, \& Trachanas, 2016). Katrakilidis and Trachanas (2012) noted that NARDL outperforms in testing cointegration in small samples, which is also true in our case. Many studies have utilized this procedure to examine if an increase and decrease in independent variable have different impact on a dependent variable (see, e.g., Katrakilidis \& Trachanas, 2012; Fousekis et al., 2016; Bahmani-Oskooee \& Ghodsi, 2017). Following these studies, we specify and estimate a nonlinear model to capture the possible asymmetric effects of ODI on economic growth. The linear equation (1) can be converted into an asymmetric equation by replacing of $f_{t}$ by its positive and negative components:

$$
y_{t}=\beta_{1} d_{t}+\beta_{2} c s_{t}+\beta_{3 t} l e_{t}+\beta_{4} i f_{t}+\beta_{5} o f_{t}^{+}+\beta_{6} o f_{t}^{-}+\varepsilon_{t} .
$$

In above equation (2), the movements in $o f_{t}$ are decomposed into its increasing and decreasing partial sum i.e. $o f_{t}=o f_{o}+o f_{t}^{+}+o f_{t}^{-}$where $o f_{t}^{+}$and $o f_{t}^{-}$are the partial sum of the positive (an increase in ODI) and the negative changes (a decrease in ODI) in $o f_{t}$. Specifically, the partial sum of positive and negative changes in $o f_{t}$ are generated by the following formulas:

$$
\begin{aligned}
& o f_{t}^{+}=\sum_{i=0}^{t} \Delta o f_{i}^{+}=\sum_{i=0}^{t} \max \left(\Delta o f_{i}, 0\right) \\
& o f_{t}^{-}=\sum_{i=0}^{t} \Delta o f_{i}^{-}=\sum_{i=0}^{t} \min \left(\Delta o f_{i}, 0\right)
\end{aligned}
$$

Following Shin et al. (2014), the partial asymmetry cointegration equation now can be obtained by replacing the positive and negative partial sum of $o f_{t}$ in the standard symmetric ARDL as:

$$
\begin{aligned}
& \Delta y_{t}=\alpha_{0}+\varphi y_{t-1}+\phi^{+} o f_{t-1}^{+}+\phi^{-} o f_{t-1}^{-}+\phi_{i f} i f_{t-1}+\phi_{c s} c s_{t-1}+\phi_{l e} l e_{t-1}+\sum_{i=1}^{p} p_{i} \Delta y_{t-i}+ \\
& \sum_{i=0}^{p} \gamma_{i f, i} \Delta i f_{t-1}+\sum_{i=0}^{p} \gamma_{c s, i} \Delta c s_{t-1}+\sum_{i=0}^{p} \gamma_{l e, i} \Delta l e_{t-1}+\sum_{i=0}^{s}\left(\gamma_{i}^{+} \Delta o f_{t-1}^{+}+\gamma_{i}^{-} o f_{t-1}^{-}\right)+\xi_{t} .
\end{aligned}
$$

In equation 5, $p, q$ and $s$ denote the lag length for the variables in the distributed lag part. Long run asymmetry effects can be tested using Wald test by evaluating the null hypothesis of symmetry $\mathrm{H}_{0}: \phi^{+}=\phi^{-}$against the alternative of asymmetry $\mathrm{H}_{1}: \phi^{+} \neq \phi^{-}$. The rejection of null indicates presence of asymmetrical effects of the outbound FDI on economic growth. The long run effects of an increase and decrease in are given by $\beta_{2}=-\phi^{+} / \alpha_{0}$ and $\beta_{3}=-\phi^{-} / \alpha_{0}$ respectively. While $\sum_{i=0}^{s} \gamma_{i}^{+}$and $\sum_{i=0}^{s} \gamma_{i}^{-}$capture the short run influence of an increase and decrease in $o f_{t}$. Thus, we also capture the asymmetric short run effects of 
$o f_{t}$ movements on economic growth. To test the existence of cointegration among the variables, Wald $F$ test is utilized to test the $\mathrm{H}_{0}: \alpha_{1}=\varphi=\phi^{+}=\phi^{-}=\phi_{i f}=0$ against the alternative $\mathrm{H}_{1}:\left\{\alpha_{1} \neq 0\right\} \cup\{\varphi \neq 0\} \cup\left\{\phi^{+} \neq 0\right\} \cup\left\{\phi^{-} \neq 0\right\} \cup\left\{\phi_{i f} \neq 0\right\}$. In case of the rejection of null hypothesis, long run and short run asymmetric relationship between outbound FDI and economic growth is examined. In addition, we can also estimate the asymmetric cumulative dynamic multiplier effects of a one percent change in $o f_{t-1}^{+}$and $o f_{t-1}^{-}$on as follow:

$$
d m_{h}^{+}=\sum_{j=0}^{h} \partial y_{t+j} / \partial o f_{t-1}^{+}, d m_{h}^{-}=\sum_{j=0}^{h} \partial y_{t+j} / \partial o f_{t-1}^{-} \quad h=0,1,2 .
$$

Note that as $h \rightarrow \infty, d m^{+}{ }_{h} \rightarrow \beta_{2}$ and $d m^{-}{ }_{h} \rightarrow \beta_{3}$ (Shin et al., 2014).

Estimated dynamic multipliers are helpful to observe the asymmetric dynamic adjustment of $o f_{t}$ and $y_{t}$ to their new steady state over time, after a shock affecting the cointegration system.

Table 1. Unit root test statistics

\begin{tabular}{|c|c|c|c|}
\hline Variable & Ng-Perron & ADF & KPSS \\
\hline$y_{t}$ & -4.081 & 0.194 & $0.683^{\star *}$ \\
\hline$o f_{t}$ & $-14.781^{\star * *}$ & $-3.631^{\star *}$ & 0.102 \\
\hline$i f_{t}$ & -2.897 & -2.239 & $0.361^{\star * *}$ \\
\hline$c s_{t}$ & $29.374^{\star}$ & $-3.941^{\star *}$ & $0.121^{\star * *}$ \\
\hline$l e_{t}$ & $-46.345^{\star}$ & -1.001 & $0.671^{\star *}$ \\
\hline$\Delta y_{t}$ & $-25.011^{\star}$ & $-4.249^{\star}$ & 0.067 \\
\hline$\Delta o f_{t}$ & $-14.721^{\star *}$ & $-7.168^{\star}$ & 0.501 \\
\hline$\Delta i f_{t}$ & $-15.411^{\star}$ & $-4.496^{\star}$ & 0.217 \\
\hline$\Delta c f_{t}$ & -2.535 & $-4.405^{\star}$ & 0.052 \\
\hline$\Delta e_{t}$ & -4.505 & $-8.345^{\star}$ & 0.132 \\
\hline
\end{tabular}

Notes: ${ }^{*},{ }^{*}$ and ${ }^{* *}$ indicate significance at $1 \%, 5 \%$ and $10 \%$, respectively. $\mathrm{H}_{0}$ : series has unit root for $\mathrm{Ng}$-Perron and ADF while $\mathrm{H}_{0}$ : series is stationary for KPSS. For Ng-Perron test, we reported only MZa statistics to save the space.

\section{Results and discussion}

For empirical analysis, in addition to asymmetric ARDL, we also estimate the model by using standard ARDL approach for comparison purpose. Implementation of ARDL method involves several steps. First, we check the order of integration of the series to confirm that none of the series is I(2). For this, we utilized Ng-Perron, ADF and KPSS unit root tests to get robust results because each test has some statistical drawbacks. Table 1 depicts that $y_{t}$ and $i f_{t}$ are first difference stationary i.e. I(1) across all the three tests whereas $l e_{t}, o f_{t}$ and $c s_{t}$ are $\mathrm{I}(0)$. The results show that our variables are $\mathrm{I}(0)$ or $\mathrm{I}(1)$ but not at $\mathrm{I}(2)$. Furthermore, all the three tests indicate that the dependent variable (i.e., $\left.y_{t}\right)$ is I(1), it satisfies the precondition of Pesaran, Shin, and Smith (2001) to apply ARDL cointegration test (Kouakou, 2011). 
Next, we use OLS method to estimate cointegration equation (5). We choose 2 lags based on FPE, AIC and HQ criteria (Table 2). Following Katrakilidis and Trachanas (2012), we also adopt the general-to-specific procedure to select the best fitted model by successively eliminating insignificant lags. The results of Wald F-test for cointegration are given in Table 3. The results show that the value of $F$-statistics for both the symmetric ARDL and NARDL is 4.94 and 4.38 , respectively, which exceed the upper critical values at the $5 \%$ level of significance. These results confirm that there exists a stable long-run relationship among the variables. After confirming cointegration, next we estimate the long run coefficients of the regressors.

Table 2. Lag length selection criteria for cointegration

\begin{tabular}{|c|c|c|c|c|c|c|}
\hline Lag & LogL & LR & FPE & AIC & SC & HQ \\
\hline 0 & -193.658 & - & 5.4932 & 15.893 & 16.136 & 15.960 \\
\hline 1 & -42.017 & 230.495 & 0.0002 & 5.761 & $7.224^{\star}$ & 6.167 \\
\hline 2 & -6.109 & $40.216^{\star}$ & $0.0001^{\star}$ & $4.888^{\star}$ & 7.570 & $5.632^{\star}$ \\
\hline
\end{tabular}

Notes: The ${ }^{\star}$ indicates lag order selected by the criterion at $5 \%$ level of significance.

Table 3. Bound cointegration test results

\begin{tabular}{|c|c|c|c|c|}
\hline \multirow{2}{*}{ Significance level } & \multicolumn{2}{|c|}{ Asymmetric ARDL } & \multicolumn{2}{c|}{ Symmetric ARDL } \\
\cline { 2 - 5 } & Lower bound & Upper bound & Lower bound & Upper bound \\
\hline $1 \%$ & 3.93 & 5.23 & 4.4 & 5.72 \\
\hline $5 \%$ & 3.12 & 4.25 & 3.47 & 4.57 \\
\hline $10 \%$ & 2.75 & 3.79 & 3.03 & 4.06 \\
\hline F-statistics & $4.38^{* *}$ & - & $4.94^{* *}$ & - \\
\hline
\end{tabular}

Notes: ${ }^{* *}$ indicates significant at 5\% level. Critical Values are cited from Pesaran et al. (2001) Table: Unrestricted intercept and unrestricted trend. Pre-whitening lags based on AIC criterion are used to calculate long-run variance.

Table 4. Long run estimation results of symmetric and asymmetric ARDL models

\begin{tabular}{|c|c|c|c|c|}
\hline \multirow{2}{*}{ Variables } & \multicolumn{2}{|c|}{ Asymmetric ARDL } & \multicolumn{2}{c|}{ Symmetric ARDL } \\
\cline { 2 - 5 } & Coefficient & t-statistics & Coefficient & t-statistics \\
\hline$o f_{t}$ & - & - & 0.011 & 0.181 \\
\hline$o f_{t}^{+}$ & $0.105^{\star}$ & 3.032 & - & - \\
\hline$o f_{t}^{-}$ & $-0.087^{\star}$ & -4.182 & - & - \\
\hline$i f_{t}$ & $0.038^{\star}$ & 3.142 & -0.004 & -0.144 \\
\hline$l_{t}$ & $7.932^{\star}$ & 2.912 & 15.159 & 0.653 \\
\hline$c s_{t}$ & $0.009^{\star}$ & 2.914 & 0.011 & $4.963^{\star}$ \\
\hline Constant & $-27.385^{\star *}$ & -2.411 & -58.068 & -0.594 \\
\hline$R^{2}$ & 0.99 & & 0.99 & \\
\hline$F$-statistics & 9449.46 & $(0.000)$ & 13229.44 & $(0.000)$ \\
\hline
\end{tabular}


End of Table 4

\begin{tabular}{|c|c|c|c|c|}
\hline \multirow{2}{*}{ Variables } & \multicolumn{2}{|c|}{ Asymmetric ARDL } & \multicolumn{2}{|c|}{ Symmetric ARDL } \\
\hline & Coefficient & t-statistics & Coefficient & t-statistics \\
\hline Asymmetric test ${ }^{\dagger}$ & $22.946^{\star}$ & $(0.000)$ & - & - \\
\hline JB & 0.639 & $(0.726)$ & 0.701 & $(0.701)$ \\
\hline RESET & 0.079 & $(0.780)$ & $3.817^{\star * *}$ & $(0.065)$ \\
\hline Arch & 0.063 & $(0.804)$ & 0.156 & $(0.697)$ \\
\hline LM & 1.392 & $(0.247)$ & 0.639 & $(0.431)$ \\
\hline
\end{tabular}

Notes: ${ }^{*}{ }^{* *}$ and ${ }^{* * *}$ indicate significant at $1 \%, 5 \%$ and $10 \%$ level, respectively. Numbers in parenthesis are the $p$-value corresponding to the diagnostic tests. ${ }^{\dagger}$ Asymmetry test is based on the $F$-statistics corresponds to the Wald test of alternative hypothesis $\mathrm{H}_{1}: \phi^{+} \neq \phi^{-}$in Eq. (5).

The results reported in Table 4 clearly indicate the presence of asymmetry effects of outbound FDI on GDP growth. Firstly, following Bahmani-Oskooee and Ghodsi (2017), the asymmetry is observed from the sign and significance of the positive and negative partial sum of outbound FDI i.e. $o f_{t}^{+}$and $o f_{t}^{-}$. As can be seen, both the $o f_{t}^{+}$and $o f_{t}^{-}$appear to be highly significant with different sign and size, implying that an increase and decrease in ODI has different impact on economic growth. Moreover, the presence of asymmetric effects of outbound FDI is also confirmed by the standard test of asymmetry suggested by Shin et al. (2014) by applying Wald test, where highly significant F-statistic (i.e., 22.946) clearly rejects the null hypothesis of symmetric effects of outbound FDI. Furthermore, the significance value of RESET specification test on symmetric model also indicates that the model in linear form is misspecified, and tends to yield biased parameter estimations.

From Table 4, we also observe that overall prediction power of the asymmetric model is much better than that of symmetric model. All the diagnostic tests (like JB, RESET, LM and $A r c h$ ) associated with asymmetric model indicate that the model is well specified. Model stability is investigated by the CUSUM and CUSUM of squares of recursive residuals tests, suggesting that the parameters are stables as the values fall inside the critical bands at $5 \%$ level (Figure 1 and Figure 2). All these facts provide strong evidences that the implementation of asymmetric model yields valid results to draw further inference.

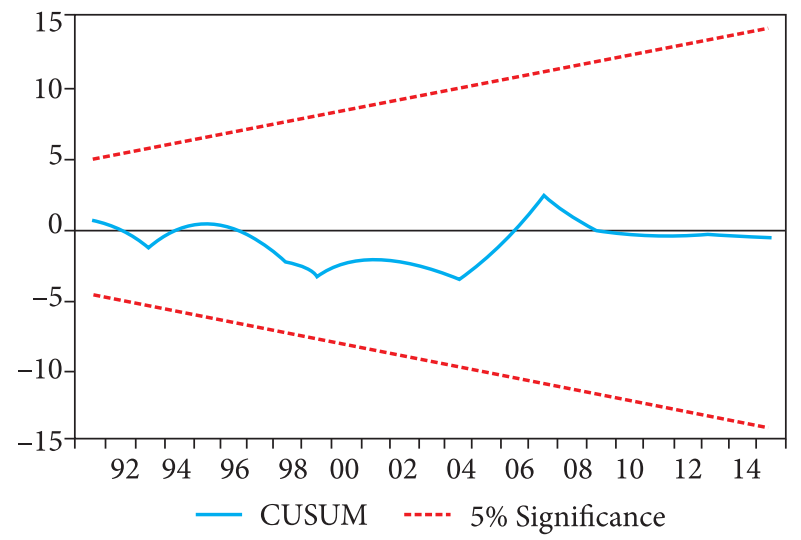

Figure 1. Plot of CUSUM of recursive residuals (Asymmetric ARDL) 


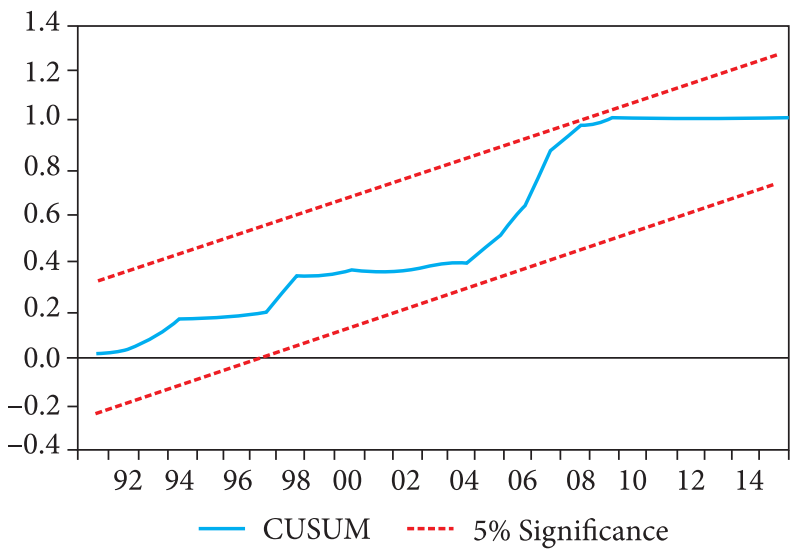

Figure 2. Plot of CUSUM of squares of recursive residuals (Asymmetric ARDL)

The long run asymmetric effects of outbound FDI on economic growth are given in Table 4. The coefficient associated with positive changes in ODI is positive and significant at $1 \%$ level, implying that an increase in ODI by 1 percent point increases economic growth by $0.105 \%$, on average. While the same changes in the short run (Table 5) brings about $0.029 \%$ increases in economic growth. These findings are consistent with new growth theories, according to which MNEs from developing countries stimulate home country's economic growth through securing access to cheaper natural resources and advanced technology in foreign markets, and their associated spillovers to local firms (Knoerich, 2017). It is also interesting to observe that the coefficient associated with a decline in ODI ( $o f_{t}^{-}$) bears negative sign, implies that a 1 percent point decrease in ODI increases economic growth by about $0.087 \%$ in the long run and about $0.024 \%$ in short run. These results indicate that both an increase and decrease in ODI increases economic growth in China. These results provide further evidence to believe that the impact of ODI on economic growth in China is asymmetric.

The results show that human and physical capital have significant and positive effects on economic growth. These results demonstrate the importance of human and physical capital on the growth prospect of the Chinese economy. It can also be regarded as the productivity gain from foreign technology transfer in the domestic markets, as suggested by Akinlo (2004). Moreover, Error Correction Term (ECM) is negative and significant at the $1 \%$ level of significance, which suggests that economic growth responds to stable long-run equilibrium, and it also confirms the long-run causality running from an increase and decrease of ODI and other variables to GDP growth.

On the other hand, all the coefficients estimated from symmetric model appeared to be insignificant for both the long run and short run. ECM is also insignificant, implying that there is no equilibrium forces that keep the model stable in the long-run. One possible reason for these results might be due to neglecting the asymmetric behavior of ODI, as pointed out by Katrakilidis and Trachanas (2012). Therefore, positive and negative separation of the ODI movement yields more significant effects that should be attributed to the nonlinear adjustment of ODI measures. It also provides an additional intuition that the failure to consider the non-linearity of a variable (ODI in our case) may conceal the true information about the equilibrium relationship among the variables. 
Table 5. Short run estimation results of symmetric and asymmetric ARDL models

\begin{tabular}{|c|c|c|c|c|}
\hline \multirow{2}{*}{ Variables } & \multicolumn{2}{|c|}{ Asymmetric ARDL } & \multicolumn{2}{c|}{ Symmetric ARDL } \\
\cline { 2 - 5 } & Coefficient & t-statistics & Coefficient & t-statistics \\
\hline$\Delta o f_{t}$ & - & - & 0.011 & 0.104 \\
\hline$\Delta o f_{t}^{+}$ & $0.029^{*}$ & 5.802 & - & - \\
\hline$\Delta o f_{t}^{-}$ & $-0.024^{\star}$ & -5.941 & - & - \\
\hline$\Delta i f_{t}$ & $0.011^{\star}$ & 6.019 & -0.005 & -0.091 \\
\hline$\Delta l e_{t}$ & $2.171^{*}$ & 4.836 & -4.661 & 1.007 \\
\hline$\Delta c f_{t}$ & $0.003^{* *}$ & 2.363 & 0.002 & 0.811 \\
\hline$E C T_{t-1}$ & $-0.274^{*}$ & -5.801 & -1.072 & \\
\hline
\end{tabular}

Notes: ${ }^{\star}$ and ${ }^{\star *}$ indicate significant level at $1 \%$ and $5 \%$, respectively.

From the results, we also observe that the magnitude of the coefficient of $o f_{t}^{+}$is about double to that of $o f_{t}^{-}$, implying that an upswing in Chinese ODI yields higher economic growth as compared to a downswing. Similarly, the results also show that the long run impact of ODI are much higher than that of the short run, as the coefficient size in the short run is about $1 / 4$ th to that of the long run. Overall, the findings indicate that the greater effect is sourcing from the positive movement in ODI in the long run.

Figure 3 reveals the dynamic asymmetric adjustment patterns of economic growth to its steady state in the long run after witnessing a shock. It is clear that economic growth responds more gradually to the positive changes in overseas investment. Particularly, economic growth responds more rapidly and significantly for the first 3 years, followed by a sluggish response between 4 to 9 years, and finally reaches to a new stable equilibrium after 16 years. On the other hand, the dynamic multipliers of the negative changes show more complex, and strongly nonlinear and rapid adjustment. First it causes a positive reaction up to 5 years after the shock strikes. This reaction is then followed by a neutral response for the next two years and finally achieves stability after about 8 years. Overall, we observe that the greater effect is

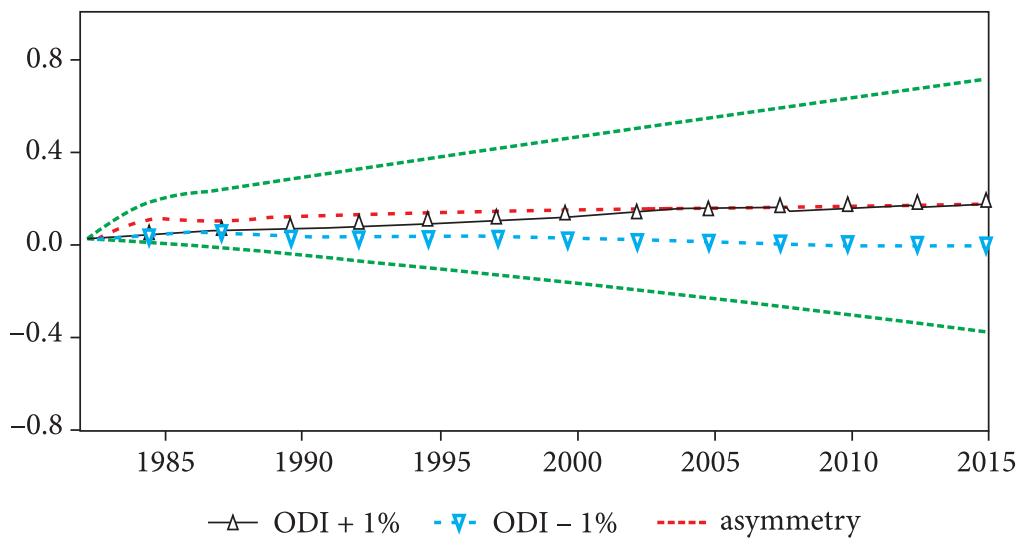

Figure 3. Cumulative asymmetric adjustments of GDP per capita to ODI 
sourcing from the positive changes in the long run, and that the economic growth effects of upward changes in ODI significantly dominates the downward changes.

Comparing with previous literature, our results are in line with many studies such as Herzer (2008, 2010), Lee (2010) and Knoerich (2017). For instance, applying dynamic OLS on panel data of 14 industrialized countries, Herzer (2008) reports that outbound FDI stimulates economic growth in the source country in the long run. According to Lee's (2010) study using time series data of Japan over the period 1977-2006, outbound FDI increases GDP growth in the long run. Similarly, Knoerich (2017) argued that outbound FDI helps emerging countries to mitigate typical problems of economic development by yielding financial, intangible capability and tangible capacity returns. Nonetheless, all these studies ignored the nonlinear measures by simply assuming that upward and downward movements in ODI hold the same effects on economic growth. Our findings provide strong evidence to believe the existence of asymmetric effects from ODI toward economic growth in China.

\section{Conclusions}

The current study explored the dynamics between economic growth and overseas investment using time series annual data of China during the period of 1982-2015. The test results suggest asymmetries in the relationship between ODI and economic growth. Thus, an asymmetric or nonlinear autoregressive distributed lag cointegration approach is used to document the potential asymmetric effects of outward FDI on economic growth in both the long run and short run. In addition, we also make a comparison between standard symmetric and asymmetric ARDL techniques to show the superiority of the later over the former.

The empirical evidences show that the relationship between ODI and economic growth is asymmetric, in contrast to the previous studies that simply assume symmetric relationship. The findings reveal that the changes in outward FDI, both an increase and decrease, have significantly positive effects on economic growth in China. However, the greater effect is sourcing from the positive changes in the long run, and that the effect of upward changes in ODI significantly dominates downward changes. More specifically, an increase in ODI by 1 percent point increases economic growth by about $0.283 \%$, while a decline in ODI by 1 percent point stimulates economic growth by about $0.169 \%$ in the long run. These findings support the idea that a reduction in overseas investment might relax the pressure on domestic credit constraints in the source country, implying an expansion in domestic investment that ultimately stimulates economic growth. Overall results of this study lend strong support to new ODI-led growth theories, which posit that firms from emerging countries conduct overseas investment in order to seek valuable input factors at lower prices and to access advanced technology which help foster economic growth of the source country through transfer and utilization of assets back in the home country or indirectly through backward and forward production linkages of MNEs with parent country.

Overall, we conclude that the imposition of a linear model to study the economic growth effects of ODI could be misleading in case of China. The use of asymmetric ARDL technique contributes to the true understanding of the nonlinear dynamics between ODI and economic growth. The findings of current study suggest that, in order to foster long-term economic 
growth, the Chinese government ought to remove barriers to ODI and should continue to encourage domestic firms to expand their businesses in foreign markets.

Though our study provides some valuable insights, the main limitation of this study is that our empirical analysis is restricted to Chinese data only which may limit the generalizability of the findings. The future research may extend our study to a broader set of indicators and countries by using asymmetric panel ARDL technique, which may provide deeper understanding of the relationship between ODI and economic growth.

\section{Funding}

This work was supported by the National Natural Science Foundation of China under Grant (number 71672019, 71271039 and 71421001).

\section{References}

Akinlo, A. E. (2004). Foreign direct investment and growth in Nigeria: An empirical investigation. Journal of Policy Modeling, 26(5), 627-639. https://doi.org/10.1016/j.jpolmod.2004.04.011

Al-Sadiq, A. (2013). Outward FDI and domestic investment: The case of developing countries (Working Paper, No. 13/52). International Monetary Fund.

Ali, U., \& Wang, J. J. (2018). Does outbound foreign direct investment crowd out domestic investment in China? Evidence from time series analysis. Global Economic Review, 47(4), 419-433. https://doi.org/10.1080/1226508X.2018.1492431

Azman-Saini, W. N. W., Baharumshah, A. Z., \& Law, S. H. (2010). Foreign direct investment, economic freedom and economic growth: International evidence. Economic Modelling, 27(5), 1079-1089. https://doi.org/10.1016/j.econmod.2010.04.001

Bahmani-Oskooee, M., \& Ghodsi, S. H. (2017). Asymmetric causality and asymmetric cointegration between Income and house prices in the United States of America. International Real Estate Review, 20(2), 127-165.

Barro, R. J., \& Sala-i-Martin, X. (2004). Economic growth (2nd ed.). Cambridge, London: The MIT Press.

Cai, K. G. (1999). Outward foreign direct investment: A novel dimension of China's integration into the regional and global economy. The China Quarterly, 160, 856-880. https://doi.org/10.1017/S0305741000001363

Child, J., \& Rodrigues, S. B. (2005). The internationalization of Chinese firms: A case for theoretical extension? Management and Organization Review, 1(3), 381-410. https://doi.org/10.1111/j.1740-8784.2005.0020a.x

Desai, M. A., Foley, C. F., \& Hines, J. R. (2005). Foreign direct investment and domestic capital stock. American Economic Review, 95(2), 33-38. http://doi.org/10.1257/000282805774670185

Dunning, J. H. (2001). The eclectic (OLI) paradigm of international production: Past, present and future. International Journal of the Economics of Business, 8(2), 173-190. https://doi.org/10.1080/13571510110051441

Eregha, P. B. (2012). The dynamic linkages between foreign direct investment and domestic investment in ECOWAS countries: A panel cointegration analysis. African Development Review, 24(3), 208-220. https://doi.org/10.1111/j.1467-8268.2012.00317.x

Fousekis, P., Katrakilidis, C., \& Trachanas, E. (2016). Vertical price transmission in the US beef sector: Evidence from the nonlinear ARDL model. Economic Modelling, 52, 499-506.

https://doi.org/10.1016/j.econmod.2015.09.030 
Fu, X. (2008). Foreign direct investment, absorptive capacity and regional innovation capabilities: Evidence from China. Oxford Development Studies, 36(1), 89-110. https://doi.org/10.1080/13600810701848193

Goh, S. K., \& Wong, K. Y. (2014). Could Inward FDI offset the substitution effect of outward FDI on domestic investment? Evidence from Malaysia. Prague Economic Papers, 23(4), 413-425. https://doi.org/10.18267/j.pep.491

Herzer, D. (2008). The long-run relationship between outward FDI and domestic output: Evidence from panel data. Economics Letters, 100, 146-149. https://doi.org/10.1016/j.econlet.2007.12.004

Herzer, D. (2010). Outward FDI and economic growth. Journal of Economic Studies, 37, 476-494. https://doi.org/10.1108/01443581011075424

Hijzen, A., Jean, S., \& Mayer, T. (2011). The effects at home of initiating production abroad: Evidence from matched French firms. Review of World Economics, 147(3), 457-483. https://doi.org/10.1007/s10290-011-0094-x

Hsu, W. C., Wang, C., \& Clegg, J. (2015). The effects of outward foreign direct investment on fixedcapital formation at home: The roles of host location and industry characteristics. Global Economic Review, 44(3), 353-368. https://doi.org/10.1080/1226508X.2015.1077720

Katrakilidis, C., \& Trachanas, E. (2012). What drives housing price dynamics in Greece: new evidence from asymmetric ARDL cointegration. Economic Modelling, 29(4), 1064-1069. https://doi.org/10.1016/j.econmod.2012.03.029

Knoerich, J. (2017). How does outward foreign direct investment contribute to economic development in less advanced home countries? Oxford Development Studies, 45(4), 443-459. http://doi.org/10.1080/13600818.2017.1283009

Kotrajaras, P. (2010). Foreign direct investment and economic growth: A comparative study among East Asian countries. Applied Economics Journal, 17(2), 12-26.

Kouakou, A. K. (2011). Economic growth and electricity consumption in Cote d'Ivoire: Evidence from time series analysis. Energy Policy, 39(6), 3638-3644. https://doi.org/10.1016/j.enpol.2011.03.069

Lai, M., Peng, S., \& Bao, Q. (2006). Technology spillovers, absorptive capacity and economic growth. China Economic Review, 17(3), 300-320. https://doi.org/10.1016/j.chieco.2006.04.005

Lecraw, D. J. (1993). Outward direct investment by Indonesian firms: Motivation and effects. Journal of International Business Studies, 24(3), 589-600. https://doi.org/10.1057/palgrave.jibs.8490247

Lee, C. G. (2010). Outward foreign direct investment and economic growth: Evidence from Japan. Global Economic Review, 39(3), 317-326. https://doi.org/10.1080/1226508X.2010.513143

Li, J., Strange, R., Ning, L., \& Sutherland, D. (2016). Outward foreign direct investment and domestic innovation performance: Evidence from China. International Business Review, 25(5), 1010-1019. https://doi.org/10.1016/j.ibusrev.2016.01.008

Li, X., \& Liu, X. (2005). Foreign direct investment and economic growth: An increasingly endogenous relationship. World Development, 33(3), 393-407. https://doi.org/10.1016/j.worlddev.2004.11.001

Pesaran, M. H., Shin, Y., \& Smith, R. J. (2001). Bounds testing approaches to the analysis of level relationships. Journal of Applied Econometrics, 16(3), 289-326. https://doi.org/10.1002/jae.616

Shin, Y., Yu, B., \& Greenwood-Nimmo, M. (2014). Modelling asymmetric cointegration and dynamic multiplier in a nonlinear ARDL framework. In R. C. Sickles \& W. C. Horrace (Eds.), Festschrift in Honor of Peter Schmidt: Econometric methods and applications (pp. 281-314). New York: Springer. https://doi.org/10.1007/978-1-4899-8008-3_9

Stevens, G. V., \& Lipsey, R. E. (1992). Interactions between domestic and foreign investment. Journal of International Money and Finance, 11(1), 40-62. https://doi.org/10.1016/0261-5606(92)90020-X

Sunesen, E. R., Jespersen, S. T., \& Telle, M. H. (2010). Impacts of EU outward FDI. In Final report. Copenhagen Economics. 
Tan, B. W., Goh, S. K., \& Wong, K. N. (2016). The effects of inward and outward FDI on domestic investment: Evidence using panel data of ASEAN-8 countries. Journal of Business Economics and Management, 17(5), 717-733. http://doi.org/10.3846/16111699.2015.1114515

Todaro, M. P., \& Smith, S. C. (2006). Economic development (9th ed.). Harlow: Pearson Education Ltd.

UNCTAD. (2006). World investment report 2006: FDI from developing and transition economies: Implications for development. United Nations: New York.

UNCTAD. (2017). World investment report 2017: Investment and the digital economy. United Nations: New York and Geneva.

Weng, Y., Yang, C. H., \& Tu, F. C. (2010). Outward foreign direct investment and product quality of domestic productions: An empirical investigation. Journal of Business Economics and Management, 11(3), 396-414. https://doi.org/10.3846/jbem.2010.19

Wesson, T. (1999). A model of asset-seeking foreign direct investment driven by demand conditions. Canadian Journal of Administrative Sciences, 16(1), 1-10. https://doi.org/10.1111/j.1936-4490.1999.tb00183.x

World Bank databank. (2017). Retrieved from http://databank.worldbank.org/data/

You, K., \& Solomon, O. H. (2015). China's outward foreign direct investment and domestic investment: An industrial level analysis. China Economic Review, 34, 249-260. https://doi.org/10.1016/j.chieco.2015.02.006

Zhang, K. H. (2006). Foreign direct investment and economic growth in China: A panel data study for 1992-2004. In Conference of WTO, China and Asian Economies, $24^{\text {th }}$ June 2006 (pp. 1-18). University of International Business and Economics, Beijing, China.

Zhang, Y., Chen, W., \& Yang, P. (2011). OFDI impact on domestic investment efficiency: Based on China's experience, in international conference of Machine Learning and Cybernetics (ICMLC), Guilin, China. IEEE, 3, 1279-1283. https://doi.org/10.1109/ICMLC.2011.6016925 